OPEN ACCESS

Edited by:

Bangzhu Zhu,

Nanjing University of Information

Science and Technology, China

Reviewed by:

Huaping Sun,

Jiangsu University, China

Tim Bian,

University of International Business and Economics, China

Minbo Xu,

Beijing Normal University, China

*Correspondence:

Zhijun Gu

gzj@szu.edu.cn

Received: 23 September 2021 Accepted: 23 November 2021

Published: 22 December 2021

Citation:

Zhang S and Gu Z (2021) Impact of Social Capital on Environmental Governance Efficiency-Behavior of

Guangdong, China.

Front. Energy Res. 9:781657. doi: 10.3389/fenrg.2021.781657

\section{Impact of Social Capital on Environmental Governance Efficiency-Behavior of Guangdong, China}

\author{
Shujian Zhang and Zhijun Gu* \\ School of Government, Shenzhen University, Shenzhen, China
}

The main purpose of this article is to investigate the impact of social capital level on environmental governance efficiency in economically developed areas. We choose China's richest province Guangdong. Compared with other Chinese provinces, Guangdong's local governments are in better fiscal status, and they can allocate environmental spending in line with the trend of gross domestic product per capita. We want to observe the important factors related to social cognition other than capital investment to gain a more profound influence on the efficiency of local environmental governance. This article assumes that the degree of local social capital will have a great positive impact on the efficiency of regional environmental governance. Superefficiency slacks-based measure method of data envelopment analysis is adopted to calculate the environmental governance efficiency by considering the expected output and the nonexpected output. Then, short-panel regression was used to analyze the relationship between social capital and environmental governance efficiency. Through an empirical analysis of urban panel data of Guangdong province from 2001 to 2019, it is found that the degree of social capital does have a significant positive impact on the efficiency of local environmental governance. After the research conclusion, we propose some policy suggestions to local governments.

Keywords: social capital, environmental governance, governance efficiency, local governance, China study

\section{INTRODUCTION}

The ecological environment protection has become a major quandary of local governance in developed areas of China, as China has experienced more than 40 years of rapid economic growth since the reform and open-up policy and has realized that economic growth must change from high-speed to high-quality way. Rapid economic growth at the expense of the environment has been very intuitively felt by citizens in their daily lives, and environmental deterioration has become the main cause of many serious diseases. In the southeastern coastal areas of China, local economic development has made great achievements, and people are beginning to pay attention to their own health problems. As southeast China is a manufacturing hub, economic growth has had a big impact on environmental protection. This has forced the government to consider policies that balance economic development and environmental governance. We chose social capital to observe the influencing factors of environmental governance efficiency in affluent 
areas. This is because social capital, as opposed to capital input and technology application, is a matter of community consciousness that is highly relevant to a region (Kaasa, 2016).

Local governments in China have been increasing investment in environmental governance, and good results have been achieved (Liu et al., 2017; Zheng et al., 2020). For residents in Chinese affluent areas, environmental governance has become a hot topic of social concern. People put forward higher request to environmental management. But the way of environmental pollution control in developed areas is obviously different from that in less developed areas, and the resulting efficiency of pollution control is also different. Therefore, it is a very meaningful topic to find the factors that affect the efficiency of environmental governance. Government spending is the main driving force for environmental pollution control across China, especially from local governments. The economically developed urban areas are relatively abundant in the investment of environmental governance, and the efficiency of environmental governance is generally not affected by the pressure of funds. Environmental protection fundamentally depends on the longterm accumulation of good cognitive foundation of residents (Moynihan \& Lavertu, 2012). Therefore, to explore the factors affecting the efficiency of environmental governance in rich areas may need to look beyond money.

An increasing number of research shows that social capital has an important impact on sustainable development such as growth, equity, and the environment (Putnam, 1995). In the long run, the efficiency of environmental governance in economically developed areas is not only related to the government's public expenditures, but also closely related to the social capital that can significantly improve the social culture and institutional environment. Regional social capital formed after long-term cognitive repair will have a positive impact on the efficiency of government governance (Krause, 2006). Social interaction and social modernization even play a decisive role in public governance (Jones and Clark, 2013). From the perspective of social cognition, strengthening the function of information transmission among people in social networks is conducive to the implementation of common decisions. Environmental protection is a positive example of this kind (Hetherington, 2001; Lyons \& Kashima, 2001; Aarøe and Petersen, 2018). Relations of social trust, common rules, norms, and sanctions and connectedness in institutions may have a vital role in evaluating governance efficiency (Pretty and Ward, 2001; Dulal et al., 2011). Each stage of environmental governance involves the behavior of enterprises and the daily life of residents, and many regulations would have a positive effect through the social environment. Social capital can improve governance performance when governmental policy fails. Effective social communication, networks, and organizations can expand the scale and effectiveness of information dissemination, which will lead to more effective enforcement of environmental governance regulations (Du and Li, 2020; Hu and Wang, 2020; Song et al., 2020). As long as social capital reaches a certain level, social trust, social norms, and participation will significantly improve the efficiency of regional environmental governance. Moreover, social capital greatly promotes the transparency of local government, and transparent government is more conducive to the utilization efficiency and supervision of environmental protection resources (Wang et al., 2020).

Some other research also reveals that the impact of social capital on environmental governance efficiency varies with regional differences (Lu et al., 2017; Yi et al., 2021). In China's eastern Yangtze delta area, this effect is even more pronounced. The supervision of environmental protection is mostly binding behavior, and residents with higher social capital level are more willing to provide information convenience and action coordination through the supervision network. Such as Yangtze delta urban agglomeration, the developed business network in the region makes it easier for people to communicate information and trust rules, which plays an important fundamental role in the improvement of social capital. A good level of trust in the rules can obviously help improve the efficiency of the government's environmental governance ( $\mathrm{Tu}$ et al., 2019; Yi et al., 2021). In this article, the major cities of Guangdong Province, the most developed province in China, were selected as the research targets. The growth trend of environmental governance input and percapita gross domestic product (GDP) in major cities in Guangdong is basically consistent, indicating that the influencing factor of environmental governance efficiency in each region is not mainly government funds (Barman and Gupta, 2010; Chen, 2015). We should observe the important factors related to social cognition other than capital investment to gain a more profound influence on the efficiency of local environmental governance.

Guangdong Province is a very wealthy region in China. Cities generally have plenty of financial aid to support environmental protection. Our research tries to find substantial factors beyond fund which would contribute a lot to the efficiency of environmental governance. This article assumes that the degree of local social capital will have a great positive impact on the efficiency of regional environmental governance. The data envelopment analysis (DEA) method is adopted to calculate the environmental governance efficiency by considering the expected output and the nonexpected output. Then short-panel regression was used to analyze the relationship between social capital and environmental governance efficiency. Through an empirical analysis of urban panel data of Guangdong province from 2001 to 2019, it is found that the degree of social capital does have a significant positive impact on the efficiency of local environmental governance. During the article's quantitative analysis, we took the influences of regional economic performance, openness degree, governmental public financial competence, fiscal transparency and local industrial structure, and the scale of area into consideration and controlled relative variables (Zhang et al., 2012; Zhao, 2010).

\section{VARIABLES AND DATA}

The data in this article are from the Statistical Yearbook of Chinese Cities and the Statistical Yearbook of Guangdong 
Province from 2001 to 2019. There are 21 cities in Guangdong Province, China. The panel data are strongly balanced, and that the number of areas is more than the number of years means it is a short panel. The dependent variable of this article is the efficiency of local environmental governance. Regional governments have invested a lot of financial expenditure to protect the ecological environment. To observe the environmental governance efficiency of regions completely, we need to take expected output and undesired output of environmental governance expenditure into consideration together.

We estimate regional efficiency based on super-efficiency slacks-based measure (SBM) method (Tone, 2001, 2010). In the analysis of traditional non-super-efficiency DEA model, multiple decision-making units (DMUs) are usually evaluated as effective; especially when the number of input-output is large, the number of effective DMU is also large. The maximum efficiency value obtained by this model is 1 , and the efficiency value of the effective DMU is the same. The efficiency of these effective DMU cannot be further distinguished. Super-efficiency model (Andersen and Petersen, 1993; Ray, 2008) by removing the evaluated DMU from the reference set, that is, the efficiency of the evaluated DMU is obtained by referring to the Frontier formed by other DMUs, solves the problem that the efficiency of effective DMU cannot be distinguished. Suppose the total number of decision units (DMU) in period $T$ is $K$, and each DMU uses $M$ input factors and produces $I$ desired outputs and $R$ undesired outputs, $\quad x_{k} \in \mathrm{R}^{M}, \quad y_{k} \in R^{I}$, and $b_{k} \in R^{R}$, respectively, represent the input vector, expected output vector, and unexpected output vector of the $\mathrm{k}$ DMU; then, the input-output of the $k$ DMU in period $t$ is expressed as $\left(x_{k}^{t}, y_{k}^{t}, b_{k}^{t}\right)$. Define the production possibility set constructed by DMU other than $D M U_{k}$ as follows:

$$
\begin{aligned}
& P^{t}=\left\{\left(x^{t}, y^{t}, b^{t}\right)\right. \\
& \left.\mid x^{t} \geq \sum_{j=1, j \neq k}^{K} x_{j}^{t} \lambda_{j}, y^{t} \leq \sum_{j=1, j \neq k}^{K} y_{j}^{t} \lambda_{j}, b^{t} \geq \sum_{j=1, j \neq k}^{K} b_{j}^{t} \lambda_{j}, \lambda_{j} \geq 0\right\}
\end{aligned}
$$

where $\lambda_{j}$ is the weight coefficient vector (intensity vector); here we assume that scale returns are variable (i.e., VRS), so the sum of weight coefficients of all DMUs is equal to 1 , i.e., $\quad \sum_{j=1, j \neq k}^{K} \lambda_{j}=1$. Here, DMU is each district in Guangdong Province, and the input variable of each area is environmental input. The expected output variable is wastewater utilization rate and solid waste treatment rate, and the unexpected output variable is sulfur dioxide and nitrogen oxide. Therefore, $M=1, I=2, R=2$.

The super-efficiency SBM efficiency value of decision unit $K$ $k \in\{1,2, \cdots, K\}$ can be obtained by solving the following programming problem:

$$
\begin{aligned}
& I E_{\text {SuperSBM }}^{t}\left(x_{k}^{t}, y_{k}^{t}, b_{k}^{t}, \lambda\right) \\
& =\min \frac{1+(1 / M) \sum_{m=1}^{M}\left(s_{m}^{x,-} / x_{m, k}^{t}\right)}{1-[1 /(I+R)]\left[\sum_{i=1}^{I}\left(s_{i}^{y,+} / y_{i, k}^{t}\right)+\sum_{r=1}^{R}\left(s_{r}^{b,-} / b_{r, k}^{t}\right)\right]}
\end{aligned}
$$

$$
\begin{gathered}
\text { s.t. } \quad \sum_{j=1, j \neq k}^{K} x_{m, j}^{t} \lambda_{j}-s_{m}^{x,-} \leq x_{m, k}^{t} \\
\sum_{j=1, j \neq k}^{K} y_{j}^{t} \lambda_{j}+s_{i}^{y,+} \geq y_{i, k}^{t} \quad \sum_{j=1, j \neq k}^{K} b_{j}^{t} \lambda_{j}-s_{r, k}^{b,-} \leq b_{r, k}^{t} \\
s^{x,-} \geq 0, s^{y,+} \geq 0, s^{b,-} \geq 0, \lambda \geq 0, \quad \sum_{j=1, j \neq k}^{K} \lambda_{j}=1 \\
m=1,2, \cdots, M ; \quad i=1,2, \cdots, I ; \quad r=1,2, \cdots, R
\end{gathered}
$$

Among them, $I E_{\text {SuperSBM }}$ stands for regional efficiency, and its value is between $(0,1)$. The larger the value is, the higher the regional efficiency is. When $I E_{\text {SuperSBM }}=1$, it means that the DMU is an effective unit; that is, it is located on the production Frontier. $s_{m}^{x,-}, s_{i}^{y,+}, s_{r}^{b,-}$, respectively, represent the relaxation variables corresponding to input variables, expected output variables, and nonexpected output variables. To solve Eq. 2, we use the method of Charnes and Cooper (1978) to convert the equation into the following linear programming problem.

$$
I E_{\text {SuperSBM_L }}^{t}\left(x_{k}^{t}, y_{k}^{t}, b_{k}^{t}, \lambda\right)=\min \tau+(1 / M) \sum_{m=1}^{M}\left(S_{m}^{x,-} / x_{m, k}^{t}\right)
$$

s.t. $1=\tau-[1 /(I+R)]\left[\sum_{i=1}^{I}\left(S_{i}^{y,+} / y_{i, k}^{t}\right)+\sum_{r=1}^{R}\left(S_{r}^{b,-} / b_{r, k}^{t}\right)\right]$

$$
\sum_{j=1, j \neq k}^{K} x_{m, j}^{t} \Lambda_{j}-S_{m}^{x,-} \leq \tau x_{m, k}^{t}
$$

$$
\sum_{j=1, j \neq k}^{K} y_{j}^{t} \Lambda_{j}+S_{i}^{y,+} \geq \tau y_{i, k}^{t}
$$

$$
\sum_{j=1, j \neq k}^{K} b_{j}^{t} \Lambda_{j}-S_{r, k}^{b,-} \leq \tau b_{r, k}^{t}
$$$$
S^{x,-} \geq 0, S^{y,+} \geq 0, S^{b,-} \geq 0, \Lambda_{j} \geq 0, \tau>0, \sum_{j=1, j \neq k}^{K} \Lambda_{j}=\tau
$$$$
m=1,2, \cdots, M ; \quad i=1,2, \cdots, I ; \quad r=1,2, \cdots, R
$$

Let the optimal solution of Eq. 3 of linear programming be ( $I E_{\text {SuperSBM_L }}^{*}, S^{x,-, *}, S^{y,+, *}, S^{b,-, *}, \tau^{*}, \Lambda^{*}$ ), then the optimal solution of the original nonlinear programming problem (2) is:

$$
\begin{gathered}
I E_{\text {SuperSBM }}^{*}=I E_{\text {SuperSBM_L}}^{*}, \quad \lambda^{*}=\Lambda^{*} / \tau^{*} \\
s^{x,-, *}=S^{x,-, *} / \tau^{*}, \quad s^{y,+, *}=S^{y,+, *} / \tau^{*}, \quad s^{b,-, *}=S^{b,-, *} / \tau^{*}
\end{gathered}
$$

Accordingly, we can also get the efficiency of each input-output variable:

$$
\begin{aligned}
& D E_{k, t}^{i n}=\left(x_{k, t}^{i n}-s_{k, t}^{i n}\right) / x_{k, t}^{i n} \\
& D E_{k, t}^{u o}=\left(b_{k, t}^{u o}-s_{k, t}^{u o}\right) / b_{k, t}^{u o} \\
& D E_{k, t}^{d o}=y_{k, t}^{d o} /\left(y_{k, t}^{d o}+s_{k, t}^{d o}\right)
\end{aligned}
$$

Among them, $D E_{k, t}^{i n}, D E_{k, t}^{u o}, D E_{k, t}^{d o}$, respectively, represent the efficiency of input variable, expected output variable, and unexpected output variable, and its value is between $(0,1)$. The larger the value is, the higher the efficiency of the input or output factor is. 
TABLE 1 | Descriptive statistics.

\begin{tabular}{lccccc}
\hline Variable & Obs & Mean & Std. Dev & Min & Max \\
\hline Efficiency & 399 & 0.9543444 & 0.6591516 & 0.032399 & 5.139752 \\
SC & 399 & 0.0003918 & 0.0005669 & 0.000066 & 0.0046407 \\
GDPpc & 399 & $43,545.62$ & $38,414.11$ & $3,164.33$ & 203489 \\
FDI & 399 & $97,821.26$ & $151,007.8$ & 1,611 & 820301 \\
Industry & 399 & $3.80 e+07$ & $5.86 e+07$ & 334,569 & $3.73 e+08$ \\
Popu & 399 & 482.7468 & 269.9292 & 128.45 & 1530.59 \\
AreaDummy & 399 & 0.4285714 & 0.495493 & 0 & 1 \\
Sufficiency & 399 & 0.5742114 & 0.2496258 & 0.1354 & 1.168413 \\
Transparency & 399 & 0.7169706 & 0.0953241 & 0.4427 & 0.9533 \\
Tertiary & 399 & 41.04193 & 8.142568 & 24.44 & 71.75 \\
Electron & 399 & $1,621,149$ & $2,217,050$ & 24,663 & $1.01 \mathrm{e}+07$
\end{tabular}

Regional social capital level (SC) is the explanatory variable in the research. Social capital is calculated based on the ratio of welfare, network, cultural, sports, and entertainment employees to total employees on duty (Villalonga-Olives and Kawachi, 2015). In local statistical yearbooks from 2001-2019 in Guangdong Province, this kind of data has good continuity and comparability and ensures panel data's overall stability (Grafton and Knowles, 2004). We chose percapita GDP (GDPpc) and total population at the end of the year (Popu) as variables to observe the population and economic development level that have a fundamental impact on the environment. In addition, we control some industrial and economic variables related to environmental protection. Generally, regional industrial structure would affect emission level so that we take the proportion of tertiary (Tertiary) as a control variable (Gonzalez and Ho, 2018). Power consumption of whole society (Electron) and regional industrial output value (Industry) indicate the level of energy consumption in the area, which are very basic variables in environment-related issues (Liang and Langbein., 2015; Xie et al., 2018). We also controlled some variables that have local characteristics in terms of openness and economic development level. The regional annual amount of foreign capital actually utilized (FDI) represents the degree of city's openness. Guangdong province has a great difference in economic development level, and the Pearl River Delta region is relatively developed. Therefore, we divide the 21 regions into two categories and take the regional dummy variable (AreaDummy) as the control variable. Below is the descriptive statistics table of variables (Table 1), which reports the summary statistics. We took the Napierian logarithm value of dependent variable environmental governance efficiency (InEfficiency) and standardized the independent variable social capital (stdSC) before using it in the regression model. We also took the Napierian logarithm value of variable of GDPpc, FDI, Industry, Popu, and Electron. As mentioned previously, Guangdong is a province with uneven development among regions. The degree of fiscal self-sufficiency varies greatly in regions (Bao and Guan, 2019; Lopez et al., 2011; Bai et al., 2019).

\section{MODEL AND RESULTS}

First, based on controlling other variables, we show the partial correlation graph between the core variable and the explained variable (Figure 1). We can initially observe the general trend of correlation between environmental governance efficiency and

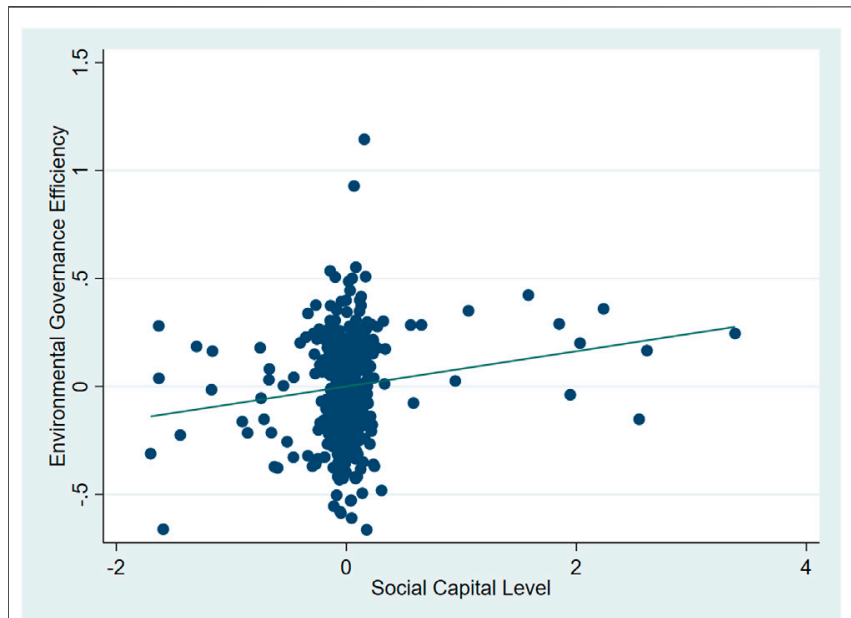

FIGURE 1 | Partial correlation graph between the core variable and the explained variable.

social capital. As each city in the province is different, there may be omitted variables that do not vary over time, and there may be time effects that do not vary geographically. Based on the above reasons, we adopted the two-way fixed-effects model:

$$
\begin{gathered}
\ln \text { Efficiency }_{i t}=\beta_{0}+\beta_{1} S C_{i t}+\delta \text { Controls }_{i t}+\mu_{i}+\gamma_{t}+\varepsilon_{i t} \\
(i=1, \cdots, 21 ; t=1, \cdots 19)
\end{gathered}
$$

We estimate the two-way fixed-effects model with its null hypothesis is $H_{0}$ : all $\mu_{i}=0$ and obtain the $p$ value corresponding to $F$ test result as 0 . It is much less than 0.01 , which indicates it refuses the null hypothesis, and we should choose the fixed-effects model. But if the error term is cross-sectional dependent, then the $F$ test result is unreliable, and we could not choose the fixed-effects model. We tested the cross-section problem, and the cross-sectional independence value is 0.653 , which is larger than the critical value of $0.1 \alpha$ level 0.136 . This indicates that the null hypothesis that there is no cross-sectional correlation is rejected; that is, the model has crosssectional correlation problems. Then, we do $F$ test of the regional dummy variable, and the $p$ value is less than 0.1 , which indicates that we can refuse the null hypothesis, and the individual effects exist. Finally, the model passes the Hausman test. The result strongly rejects the null hypothesis, and we choose the fixed-effects model.

To ensure the robustness of the model, we observe three more regression results through controlling different important variables. The theme of this article is to study the impact of social capital on the efficiency of environmental governance. Traditionally, the influence of economic factors, development model factors, and public finance factors on environmental governance is generally emphasized (Gupta and Miranda, 1995). Therefore, when we test the stability of the influence of social capital, we give special consideration to controlling variables with such factors. In different regressions, we, respectively, control the fiscal self-sufficiency level, economic development level, economic openness, industrial structure, energy consumption, and production capacity of different cities and observe the stability of the model results from different perspectives. The results show that the results of the model are stable in all aspects, and social capital has a significant positive 
TABLE 2 | Benchmark regression results.

\begin{tabular}{|c|c|c|c|c|c|}
\hline & (1) & (2) & (3) & (4) & (5) \\
\hline & OLS & $\mathrm{FE}$ & FE & $\mathrm{FE}$ & FE \\
\hline stdSC & $\begin{array}{l}0.129^{\star \star \star} \\
(7.54)\end{array}$ & $\begin{array}{l}0.111^{\star \star \star} \\
(8.15)\end{array}$ & $\begin{array}{l}0.107^{\star \star \star} \\
(8.03)\end{array}$ & $\begin{array}{l}0.121^{\star \star \star} \\
(8.12)\end{array}$ & $\begin{array}{l}0.118^{\star \star \star} \\
(7.95)\end{array}$ \\
\hline InPopu & $\begin{array}{l}-0.0974^{*} \\
(-2.26)\end{array}$ & $\begin{array}{l}0.0511 \\
(0.22)\end{array}$ & $\begin{array}{l}-0.112 \\
(-0.50)\end{array}$ & $\begin{array}{l}0.118 \\
(0.50)\end{array}$ & $\begin{array}{l}0.122 \\
(0.53)\end{array}$ \\
\hline AreaDummy & $\begin{array}{l}-0.100 \\
(-1.56)\end{array}$ & $\begin{array}{l}0 \\
\text { (.) }\end{array}$ & $\begin{array}{l}0 \\
(.)\end{array}$ & $\begin{array}{l}0 \\
(.)\end{array}$ & $\begin{array}{l}0 \\
(.)\end{array}$ \\
\hline InGDPpc & $\begin{array}{l}-0.0610 \\
(-1.24)\end{array}$ & $\begin{array}{l}-0.145^{\star \star} \\
(-2.59)\end{array}$ & & $\begin{array}{l}-0.145^{\star} \\
(-2.31)\end{array}$ & $\begin{array}{l}-0.0914 \\
(-1.86)\end{array}$ \\
\hline Sufficiency & & & $\begin{array}{l}-0.0222 \\
(-0.21)\end{array}$ & & \\
\hline InFDI & $\begin{array}{l}0.0290 \\
(1.39)\end{array}$ & $\begin{array}{l}0.0184 \\
(0.67)\end{array}$ & $\begin{array}{l}0.0340 \\
(1.23)\end{array}$ & & $\begin{array}{l}0.0277 \\
(0.98)\end{array}$ \\
\hline Tertiary & & & & $\begin{array}{l}-0.000971 \\
(-0.25)\end{array}$ & \\
\hline Inlndustry & $\begin{array}{l}0.0404 \\
(1.15)\end{array}$ & $\begin{array}{l}0.0727^{\star} \\
(2.02)\end{array}$ & $\begin{array}{l}-0.000124 \\
(-0.01)\end{array}$ & $\begin{array}{l}0.0713 \\
(1.88)\end{array}$ & \\
\hline InElectron & & & & & $\begin{array}{l}0.0330 \\
(1.01)\end{array}$ \\
\hline _cons & $\begin{array}{l}0.911^{\star \star} \\
(3.17)\end{array}$ & $\begin{array}{l}0.417 \\
(0.37)\end{array}$ & $\begin{array}{l}0.958 \\
(0.86)\end{array}$ & $\begin{array}{l}0.266 \\
(0.22)\end{array}$ & $\begin{array}{l}0.0982 \\
(0.09)\end{array}$ \\
\hline$N$ & 399 & 399 & 399 & 399 & 399 \\
\hline
\end{tabular}

impact on the efficiency of environmental governance. Table 2 shows the result report of all regressions in this article.

\section{CONCLUSION AND POLICY SUGGESTIONS}

This article studies the efficiency of environmental governance from a relatively new perspective of social cognition, and we have obtained good research results. Especially in Guangdong province of China, where the economy is developed and government governance is relatively transparent, this study is of great practical significance. Compared with the underdeveloped central and western regions in China, the local governments of Guangdong province are generally abundant in financial funds. To investigate the level of government governance in rich areas, we must pay more attention to social factors. Of course, the regional differences within Guangdong province are also obvious. We have controlled for that in our study.

The improvement of environmental governance efficiency is not a pure administrative or an absolute economic efficiency problem. Under the premise of sufficient government input, whether people's awareness of social community will be transmitted to the efficiency of environmental governance is a problem worthy of discussion. Our article attempted this effort. We maintain the objectivity of the data and the continuity and balance of the availability of the data in the processing of the explained variables and the main explained variables. We estimate regional efficiency based on superefficiency SBM method, fully considering reasonable expected and unexpected output. The results are very encouraging.

Social capital is a concept in which social cognition influences social norms and thus the behavior of the society as a whole. A good level of social capital is conducive to the better implementation of many regulations of the government. Environmental governance involves all aspects of the society, which requires the government to strictly supervise the behavior of enterprises, and at the same time, it also needs to strengthen the guidance of the behavior norms of all social members. This is the fundamental way to improve the efficiency of environmental governance. From the research results, we believe that social capital does have a significant positive impact on the efficiency of environmental governance. It is even more important to study such issues in an affluent region such as Guangdong. China also attaches great importance to improving social capital while building its economy.

We believe that this conclusion is a positive signal for the government to step up efforts to improve the level of social capital in the region. First, the government can achieve the basic goal of improving social capital by promoting the concept of harmonious coexistence between man and nature. This is one of the important tasks of the current government on the construction of ecological civilization. People will gradually realize the long-term positive impact of overall environmental protection awareness on improving the efficiency of environmental governance. Second, the government needs to build more abundant social and environmental governance organizations. Improving social capital requires not only the cognitive base of all social members, but also more participation in relevant environmental protection organizations. People can better share relevant information and scientific knowledge in more organizations, thus promoting the active support of social members for environmental governance policies. Again, the government should encourage social supervision of environmental governance behavior. Specific incentive measures may include regular or irregular knowledge tests, competitions, and other activities, relying on some organizations, which help publicize the environmental protection concepts. The government can provide both material and nonmaterial incentives for related activities. This can make more and more residents willing to join in the big network of improving environmental governance. It also encourages people to be more willing to contribute ideas and share them on improving the efficiency of environmental governance. Each of these policies will promote the level of social capital associated with environmental protection.

\section{DATA AVAILABILITY STATEMENT}

The original contributions presented in the study are included in the article/supplementary material, further inquiries can be directed to the corresponding author.

\section{AUTHOR CONTRIBUTIONS}

SZ contributed in quantitative research part and ZG contributed in qualitative research part.

\section{FUNDING}

National Social Science Fund of China, Award No. 18ZDA004 and Department of Education of Guangdong Province, Award No. 2020GXJK031. 


\section{REFERENCES}

Aarøe, L., and Petersen, M. B. (2018). Cognitive Biases and Communication Strength in Social Networks: the Case of Episodic Frames. Br. J. Polit. Sci. 50 (4), 1561-1581. doi:10.1017/S0007123418000273

Andersen, P., and Petersen, N. C. (1993). A Procedure for Ranking Efficient Units in Data Envelopment Analysis. Manag. Sci. 39 (10), 1261-1264. doi:10.1287/ mnsc.39.10.1261

Bai, J., Lu, J., and Li, S. (2019). Fiscal Pressure, Tax Competition and Environmental Pollution. Environ. Resource Econ. 73, 431-447. doi:10.1007/ s10640-018-0269-1

Bao, G., and Guan, B. (2019). Does Fiscal Pressure Reduce the Environmental Efficiency of Local Governments: A Moderated Mediation Model. China Population. Resour. Environ. 29 (4), 38-48. doi:10.12062/cpre.20181102

Barman, T. R., and Gupta, M. R. (2010). Public Expenditure, Environment, and Economic Growth. J. Public Econ. Theor. 12 (6), 1109-1134. doi:10.1111/j.14679779.2010.01487.x

Charnes, A., Cooper, W. W., and Rhodes, E. (1978). Measuring the Efficiency of Decision Making Units. Eur. J. Oper. Res. 2 (6), 429-444. doi:10.1016/03772217(78)90138-8

Chen, S. (2015). Environmental Pollution Emissions, Regional Productivity Growth and Ecological Economic Development in China. China Econ. Rev. 35, 171-182. doi:10.1016/j.chieco.2014.08.005

Du, W., and Li, M. (2020). Assessing the Impact of Environmental Regulation on Pollution Abatement and Collaborative Emissions Reduction: Micro-evidence from Chinese Industrial Enterprises. Environ. Impact Assess. Rev. 82, 106382. doi:10.1016/j.eiar.2020.106382

Dulal, H. B., Foa, R., and Knowles, S. (2011). Social Capital and Cross-Country Environmental Performance. J. Environ. Dev. 20 (2), 121-144. doi:10.1177/ 1070496511405153

Freire-González, J., and Ho, M. (2018). Environmental Fiscal Reform and the Double Dividend: Evidence from a Dynamic General Equilibrium Model. Sustainability 10 (2), 501-519. doi:10.3390/su10020501

Grafton, R. Q., and Knowles, S. (2004). Social Capital and National Environmental Performance: a Cross-Sectional Analysis. J. Environ. Dev. 13 (4), 336-370. doi:10.1177/1070496504271417

Gupta, S., Miranda, K., and Parry, I. (1995). Public Expenditure Policy and the Environment: a Review and Synthesis. World Dev. 23 (3), 515-528. doi:10.1016/ 0305-750X(94)00139-P

Hetherington, M. J. (2001). Resurgent Mass Partisanship: the Role of Elite Polarization. Am. Polit. Sci. Rev. 95 (3), 619-631. doi:10.1017/ S0003055401003045

$\mathrm{Hu}$, W., and Wang, D. (2020). How Does Environmental Regulation Influence China's Carbon Productivity? an Empirical Analysis Based on the Spatial Spillover Effect. J. Clean. Prod. 257, 120484. doi:10.1016/j.jclepro.2020.120484

Jones, N., and Clark, J. R. A. (2013). Social Capital and Climate Change Mitigation in Coastal Areas: a Review of Current Debates and Identification of Future Research Directions. Ocean Coastal Manag. 80, 12-19. doi:10.1016/ j.ocecoaman.2013.03.009

Kaasa, A. (2016). Social Capital, Institutional Quality and Productivity: Evidence from European Regions. Econ. Sociol. 9 (4), 11-26. doi:10.14254/2071789X.2016/9-4/1

Krause, G. A. (2006). Beyond the Norm: Cognitive Biases and the Behavioral Underpinnings of U.S. Rationality Soc. 18, 157-191. doi:10.1177/ 1043463106063322

Liang, J., and Langbein, L. (2015). Performance Management, High-Powered Incentives, and Environmental Policies in China. Int. Public Manag. J. 18 (3), 346-385. doi:10.1080/10967494.2015.1043167

Liu, Y., Xing, P., and Liu, J. (2017). Environmental Performance Evaluation of Different Municipal Solid Waste Management Scenarios in China. Resour. Conservation Recycling 125, 98-106. doi:10.1016/j.resconrec.2017.06.005

López, R., Galinato, G. I., and Islam, A. (2011). Fiscal Spending and the Environment: Theory and Empirics. J. Environ. Econ. Manag. 62 (2), 180-198. doi:10.1016/j.jeem.2011.03.001

Lu, J.-W., Zhang, S., Hai, J., and Lei, M. (2017). Status and Perspectives of Municipal Solid Waste Incineration in China: A Comparison with
Developed Regions. Waste Manag. 69, 170-186. doi:10.1016/ j.wasman.2017.04.014

Lyons, A., and Kashima, Y. (2001). The Reproduction of Culture: Communication Processes Tend to Maintain Cultural Stereotypes. Soc. Cogn. 19 (3), 372-394. doi:10.1521/soco.19.3.372.21470

Moynihan, D. P., and Lavertu, S. (2012). Cognitive Biases in Governing: Technology Preferences in Election Administration. Public Adm. Rev. 72 (1), 68-77. doi:10.1111/j.1540-6210.2011.02478.x

Pretty, J., and Ward, H. (2001). Social Capital and the Environment. World Dev. 29 (2), 209-227. doi:10.1016/S0305-750X(00)00098-X

Putnam, R. D. (1995). Bowling Alone: America's Declining Social Capital. J. Democracy 6 (1), 65-78. doi:10.1353/jod.1995.0002

Ray, S. C. (2008). The Directional Distance Function and Measurement of Superefficiency: an Application to Airlines Data. J. Oper. Res. Soc. 59 (6), 788-797. doi:10.1057/palgrave.jors.2602392

Song, Y., Yang, T., Li, Z., Zhang, X., and Zhang, M. (2020). Research on the Direct and Indirect Effects of Environmental Regulation on Environmental Pollution: Empirical Evidence from 253 Prefecture-Level Cities in China. J. Clean. Prod. 269 (9), 122425. doi:10.1016/j.jclepro.2020.122425

Tone, K. (2001). A Slacks-Based Measure of Super Efficiency-In Data Envelopment Analysis. Eur. J. Oper. Res. 130 (3), 32-41. doi:10.1016/S0377-2217(99)00407-5

Tone, K. (2010). Variations on the Theme of Slacks-Based Measure of Efficiency in DEA. Eur. J. Oper. Res. 200, 901-907. doi:10.1016/j.cie.2021.10747410.1016/ j.ejor.2009.01.027

Tu, Z., Hu, T., and Shen, R. (2019). Evaluating Public Participation Impact on Environmental protection and Ecological Efficiency in China: Evidence from PITI Disclosure. China Econ. Rev. 55, 111-123. doi:10.1016/j.chieco.2019.03.010

Villalonga-Olives, E., and Kawachi, I. (2015). The Measurement of Social Capital. Gaceta Sanitaria 29 (1), 62-64. doi:10.1016/j.gaceta.2014.09.006

Wang, Y., Xiong, J., Li, W., Na, M., and Yao, M. (2020). The Effect of Social Capital on Environmental Pollution in China-Suppression or Promotion? Ijerph 17, 9459. doi:10.3390/ijerph17249459

Xie, B.-C., Gao, J., Zhang, S., Pang, R.-Z., and Zhang, Z. (2018). The Environmental Efficiency Analysis of China's Power Generation Sector Based on Game CrossEfficiency Approach. Struct. Change Econ. Dyn. 46, 126-135. doi:10.1016/ j.strueco.2018.05.002

Yi, H., Yang, Y., and Zhou, C. (2021). The Impact of Collaboration Network on Water Resource Governance Performance: Evidence from China's Yangtze River Delta Region. Ijerph 18, 2557-57. doi:10.3390/ijerph18052557

Zhang, S., Zhang, J., and Chen, S. (2012). Assessment of Local Public Finance Performance in China when Undesirable Fiscal Phenomena Are Taken into Account. Chinas World Economy 20 (6), 82-101. doi:10.1111/j.1749124X.2012.12003.x

Zhao, X. (2010). The Relationship between Social Capital and Economic Growth and Environmental Impact. Chin. Popul. Resour. Environ. 20 (2), 68-73. doi:10.3969/j.issn.1002-2104.2010.02.012

Zheng, Y., Peng, J., Xiao, J., Su, P., and Li, S. (2020). Industrial Structure Transformation and Provincial Heterogeneity Characteristics Evolution of Air Pollution: Evidence of a Threshold Effect from China. Atmos. Pollut Res. 11 (3), 598-609. doi:10.1016/j.apr.2019.12.011

Conflict of Interest: The authors declare that the research was conducted in the absence of any commercial or financial relationships that could be construed as a potential conflict of interest.

Publisher's Note: All claims expressed in this article are solely those of the authors and do not necessarily represent those of their affiliated organizations, or those of the publisher, the editors and the reviewers. Any product that may be evaluated in this article, or claim that may be made by its manufacturer, is not guaranteed or endorsed by the publisher.

Copyright (C) 2021 Zhang and Gu. This is an open-access article distributed under the terms of the Creative Commons Attribution License (CC BY). The use, distribution or reproduction in other forums is permitted, provided the original author(s) and the copyright owner(s) are credited and that the original publication in this journal is cited, in accordance with accepted academic practice. No use, distribution or reproduction is permitted which does not comply with these terms. 